\title{
Green, Affordable Housing: Enhancing Residential Operational Utility Efficiency for Low-income Households. A Integrated Systems Thinking Approach.
}

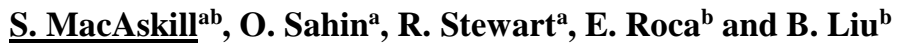 \\ ${ }^{a}$ CITIES Research Institute, Griffith University School of Engineering, Queensland \\ ${ }^{b}$ Griffith University School of Business, Queensland \\ Email: Stefen.MacAskill@ griffithuni.edu.au
}

\begin{abstract}
Housing affordability subsidies to low and middle income households consistently represent an approximate annual expenditure in excess of \$1.9 billion AUD to the Australian taxpayer. The National Rental Affordability Scheme (NRAS) is being phased out, presenting an opportunity to innovate for polices which are targeted to the amelioration of 'housing stress' for low-middle income households.

Escalating energy and water expenses are increasing net housing costs for average Australian households at a rate in excess of the consumer price index. By metrics of 'housing stress'- low and middle income households are most affected. Whilst escalating utility rates apply increasing pressure on households bottom line, conversely, investments made in operational efficiency improvements early in a buildings lifecycle improve the overall net present value proposition when looking at ongoing government housing affordability subsidies as a system.
\end{abstract}

Developers and landlords have been reluctant to invest in 'Green building' principles for low-middle income rental developments due to a lack of incentive. In an era of globally compressing bond yields, the emergence alternate 'low-carbon' funding sources (ie. Green Bonds) present an opportunity to channel a burgeoning 'Socially Responsible Investment' (SRI) portfolio from institutional investors towards the affordable housing problem, whilst promoting a national effort towards a 'green economy' and carbon-reduction commitments made under the UN Framework Convention(s) on Climate Change. This opportunity is particularly relevant when backed by government.

The success of the adoption of NRAS by the private (and later) institutional sector has demonstrated that there is a strong appetite for long term (10 year fixed income) government backed policies offering a reliable (and arguably generous) return on investment for those dwellings accepted into the NRAS pool.

Data has been analysed for an average Brisbane apartment building, suitable to low-middle income households. At current utility escalation rates (not inclusive of connection fees), utility consumption costs borne by the tenant comprise approximately $8-15 \%$ (1 to 3-bedroom units respectively) of total housing costs over a 10 year period (2016-2026). An initial investment into green building principles (such as operationally efficient lighting, appliances) from the beginning of the period can reduce these costs by $1.7-3.8 \%$ respectively. The study found that these 'green' 'low carbon' improvements could be offset through the effective use of low interest debt- particularly via the issuance of a government backed 'Green Bond'.

This paper shall expand upon this analysis, testing a variety of scenarios with systems dynamics. The complex interconnection between the variety of stakeholders involved in the delivery and management of social/affordable housing developments in Australia will be explored. These main stakeholders include Government (Federal, Local and State), Developers, Investors (private and institutional) and Tenants.

Keywords: $\quad$ Green economy, National Rental Affordability Scheme, low income housing, housing stress 
MacAskill et al., Enhancing Residential Operational Utility Efficiency for Low-income Households. A Integrated Systems Thinking Approach.

\section{INTRODUCTION}

\subsection{Affordable Housing - Governance and Policy}

Housing affordability and the economy are inextricably linked. In the three decades to 2015, Australia's house prices trebled and its median house price to median income ratio almost doubled (Yates 2016). These increases are reflected in increasing rental prices. Most vulnerable to these pricing increases are low-income households, who's wages have not increased at the same rate (ABS 2016).

Defining 'affordable housing' is often misconstrued under several guises; subjective by definition, and perspectives differing between countries and regions. In Australia, in the case of low-income households (the bottom two income deciles), there is broad agreement that housing is considered 'affordable' when it does not consume more than 30 per cent of household income (National Housing Strategy 1992). 'Housing stress' can be attributed to those low-income households who spend more than 30 per cent of their income on accommodation (Yates 2008).

Over the past several decades, numerous government policies have been implemented with the aim to mitigate housing stress for low-income Australian households. In a 2013 senate submission 'Australian Housing Policy: 50 Years of Failure', (Eslake, 2013) argues that initiatives to date have served to inflate the demand for housing, whilst failing to facilitate the delivery of new housing. Further, ownership of residential real estate is concentrated among higher income groups- those within the top $20 \%$ of the income distribution ranking (ABS, 2013). This has served to exacerbate inequalities in the distribution of income and wealth. Government policies have been argued to reduce housing affordability; counterproductive to their intent. Institutional Investment

Residential utility costs have been escalating at a greater rate than the consumer price index (ABS, 2016), further exacerbating the housing affordability problem. There has been a consistent and growing body of research on 'green certified buildings' which has suggested that operational efficiency improvements in buildings present a competitive business case in terms of annual rate of return, when compared with alternatives. Compressing investment yields in other sectors have increased the attractiveness of investments in this sector, with long term dividends being paid through a reduction in operational utility expenses. Energy and water efficient buildings represent a stable asset class, which can deliver value over a long lifecycle (often 100 year design case). Owner-occupied commercial real estate, including offices and warehouses have primarily been the beneficiaries of operational efficiency expenditure, although in this case, the inherent interconnectedness of government supported residential housing to address the needs of low-income households presents an opportunity to improve the overall effectiveness of the system. By definition, the intent of the program is to improve the affordability of housing; for renters, annual utility expenditure comprises approximately 4-10 per cent of total rental cost in Brisbane, Queensland (EME 2016). Investment in operational efficiency for residential buildings can in return improve housing affordability to eligible households, with the ultimate effect of improving affordability outcomes or by returning dividends through an offset of required government subsidy.

\section{STUDY OBJECTIVE}

The overarching objective of the study investigates the impact, to a variety of stakeholders, a change in the approach of government subsidies targeted to improve rental affordability to households facing housing stress. The main focus will be on a 'green' or 'operational utility efficiency' incentive tranche within a scheme with similar characteristics to the previous National Rental Affordability Scheme (NRAS). Alternative financing sources will also be explored.

A preliminary policy scoping study has been undertaken which mirrors the (now defunct) National Rental Affordability Scheme (NRAS), however with a number of changes. The revised scheme provides an incentive to improving operational utility performance of rental dwellings to low income households. The 'green buildings' incentive effectively serves the same overriding purpose in achieving reduced net household expenditure, however, is expected to more effectively retain value within the 'system', whilst contributing to a number of positive externalities across social, economic and political spheres- exacerbated with national/state implementation. 
MacAskill et al., Enhancing Residential Operational Utility Efficiency for Low-income Households. A Integrated Systems Thinking Approach.

The overarching goal of the National Rental Affordability Scheme has been to subsidise rental housing costs for eligible low-middle income households across Australia. It aims to reduce 'housing stress' for those households who spend more than $30 \%$ of their gross income on housing expenses. The scheme has been largely supported by private landlords who apply to have their real estate assets within the pool, in exchange for generous annual cash or tax incentives for a period of 10 years, and up to $80 \%$ of the properties market rent. Figure 1 summarises the NRAS process, which will adapted in this study.

A systems thinking approach will be applied to assess the impact of a contemporary government subsidy scheme, mirroring that of the previous National Rental Affordability Scheme. The proposed revised scheme is intended to incentivise operational utility efficiency for those residential dwellings which are eligible for let within the pool. This may be in the form of a partial direct subsidy to improve the operational efficiency of those dwellings, as a tranche within the net cash/tax incentive to the landlord. Contextually, the intended policies are to decrease housing costs for the target group- such that the net benefit to the tenant is at minimuma $20 \%$ reduction on gross rent from market rates. This shall be via a mix of a direct government subsidy, in addition to the indirect ongoing utility savings through efficiency improvement investments.

The revised scheme aims to retain value within the system, through these

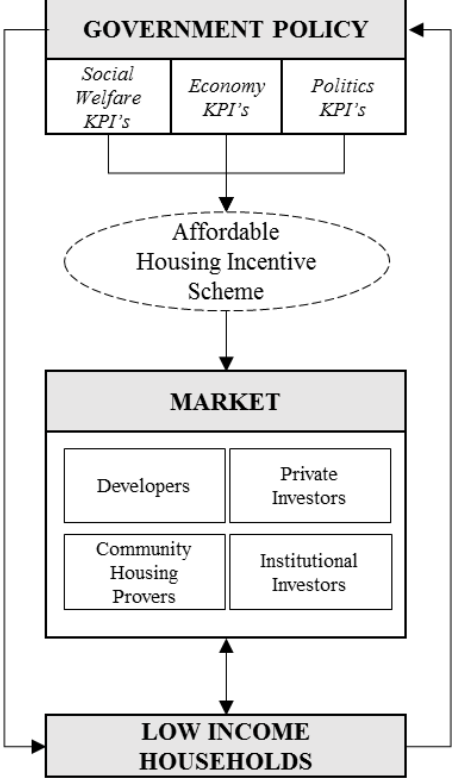

Figure 1. Government affordable housing policy. improvements over business as usual operations. The focus of the value capture will be within the impact of the operational utility or 'Green Building' improvements.

Operational utility costs as a function of household income (the determinant of 'housing stress') is the primary focus, including all contributing factors.

There are a variety of stakeholders involved in the provision of affordable housing to low and middle income households in Australia; each with their own objectives and requirements. The dynamic interaction between the stakeholders is conducive to systems thinking. Incentives cannot be adequately assessed in isolation, therefore this study applies a holistic approach.

Figure 2 represents a high-level summary of the four key stakeholders involved in affordable housing delivery in Australia. Each stakeholder represents a deeper set of interconnected influences and varying objectives determining their role within the delivery of affordable housing. The study will examine the effect of policy changes targeted to operational utility efficiency as they relate to economic, social and political spheres of influence. Behaviour of each of the stakeholders as they aim to meet their varying objectives will influence each of the spheres of influence, conversely, changes in the spheres of influence will impact stakeholder objectives and therefore outcomes.

A range of factors influence a households propensity to fall into 'housing stress'. These are closely tied with the spheres of influence. Households which are facing housing stress in turn exert influences on these spheres in a consistent feedback loop.

This project will build upon previous case studies which have explored average 'business as usual' electricity, water and gas consumption. Enhanced operational efficiency objectives will be investigated. Principles used in 'green building' rating schemes such as Green Star and NaTHERS will be applied.

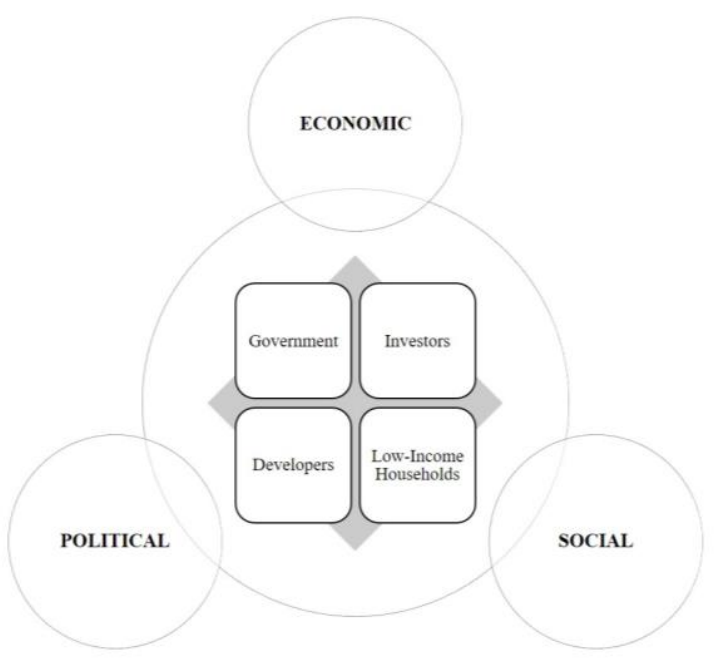

Figure 2. Key stakeholders and spheres of influence. 
MacAskill et al., Enhancing Residential Operational Utility Efficiency for Low-income Households. A Integrated Systems Thinking Approach.

\section{METHODOLOGY}

Given the dynamics, interdependencies and variety of the variables which influence housing stress, a systems thinking approach will be applied to test any changes in the incentive structure. Many of these impacts are non-linear, and require accountability of feedback effects. The application of Systems Dynamic Modelling to this issue is expected to encapsulate the wide variety of influences and impacts to change. Systems Dynamics is a powerful computer-aided modelling approach, initially developed and applied in the fields of engineering and management. Systems thinking approaches represent the behavior of complex systems (Sterman 2000, Sahin and Mohamed 2013, Sahin, Bertone et al. 2017).

\subsection{Study Process}

Throughout the varying stages of the project, key performance indicators will be assessed and improved. Stage 1 has commenced, which includes refining the study objectives and focus of the model. Existing data on household operational utility costs (and realistic efficiency targets) of NRAS dwellings will assist with the model development. Stage 2 will involve a stakeholder consultation for practitioners working in delivering and financing affordable housing units in the Queensland region. A workshop will be held to inform a matrix against key variables, including key opportunities and constraints to a revision in a government incentive scheme. The workshop will prioritise problem scoping which will form the conceptual model based on the matrix. During Stage 3 a systems model will be developed to capture the interconnected influences and variables. Stage 4 involves further development of the model, and refining based on the stakeholder feedback. Throughout

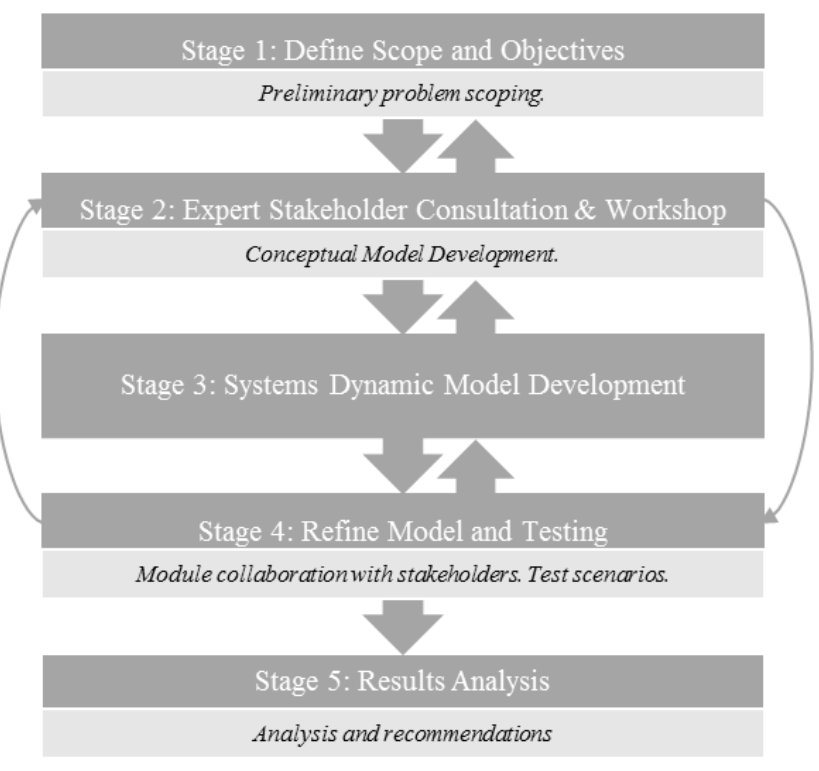

Figure 3. Process Chart. the process, key stakeholders will be engaged. During the final stage, Stage 5, an analysis of the proposed scheme will provide recommendations and a sensitivity analysis of the scheme. The study process is summarised in Figure 3.

\subsection{Engagement Strategy}

The study will draw upon the support of the National Affordable Housing Consortium, presently one of the largest not for profit affordable housing providers in Australia. The consortia brings together a range of stakeholders from management, government (federal, state and local), tenants, investors and developers. Initial scoping has determined the varying stakeholder concerns, opportunities and constraints which will influence the system. These variables shall be expanded during a number of stakeholder workshops. An initial pilot study will be designed with inputs from key stakeholders. This will ensure cause and effect of policy changes are well grounded, with measurable impact.

\subsection{Scoping Housing Stress Influence}

A conceptual systems model for 'housing stress' was developed. External influencers of 'housing stress' vs factors 'housing stress' influences were considered. Whilst there is a significant array of externalities which contribute to housing stress, this study shall primarily focus on the operational utility expenditure component- as a function of household income.

Figure 4 overleaf highlights the conceptual systems model which will be further developed. 
MacAskill et al., Enhancing Residential Operational Utility Efficiency for Low-income Households. A Integrated Systems Thinking Approach.

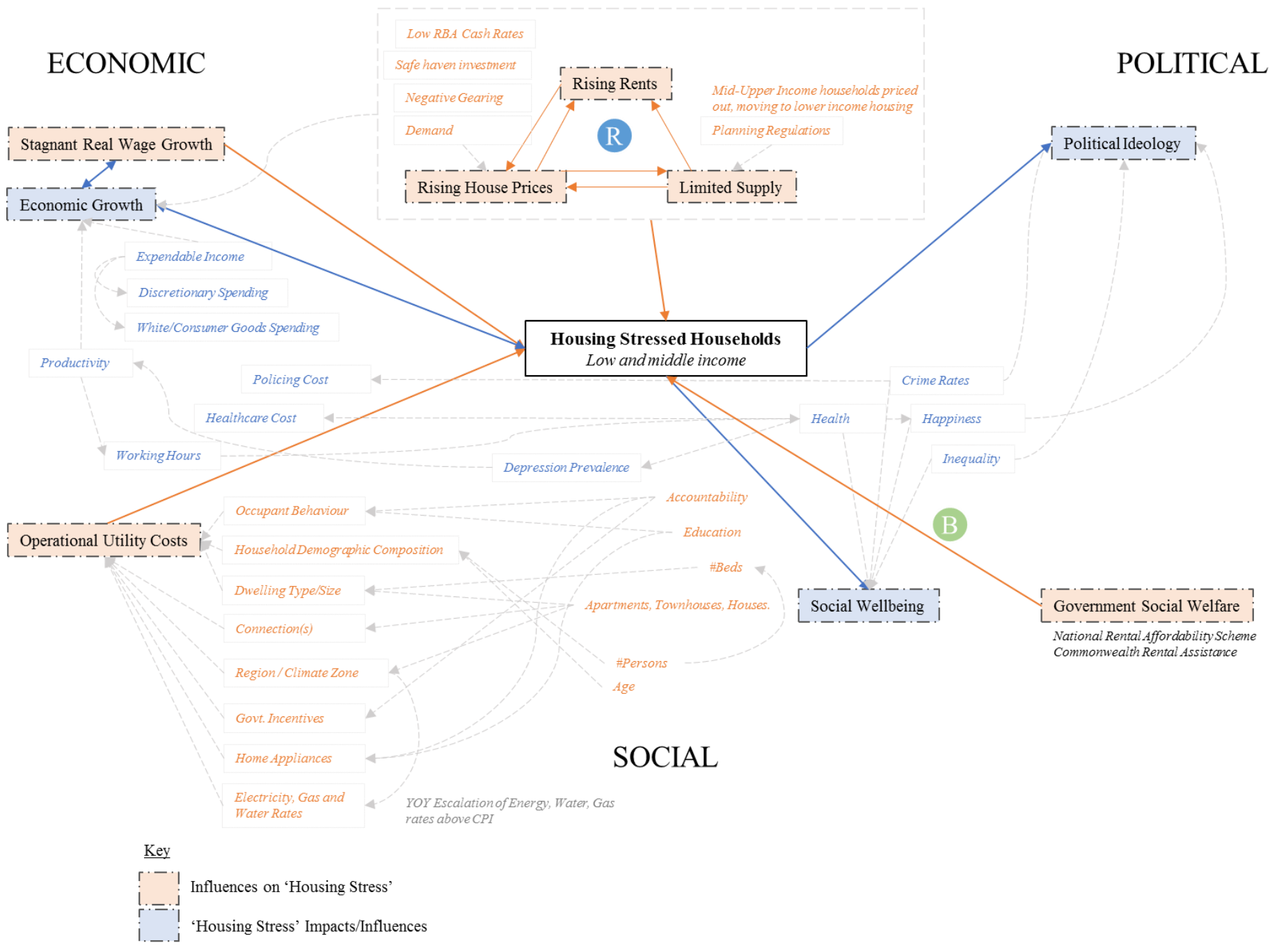

Figure 4. Conceptual scoping framework used to assess housing stress Influences and Impacts.

\section{DISCUSSION AND CONCLUSIONS}

The revised housing affordability model will aim to reduce 'housing stress' on low and middle income in Australia through an innovative approach to the issue. The weekly financial savings through energy and water efficiency programs over business as usual are anticipated to be minimal on a nominal basis; however, when taken in aggregate, are expected to exert a wider 'web' of positive influences in the Economic, Social and Political spheres of influence. Government spending towards the amelioration of housing stress presents an opportunity to positively influence other key aspects of a national, progressive agenda.

The findings of the study may inform considerations to future policy directions. Particularly, with consideration to the arguably ineffective track record of housing affordability policies in Australia over the past several decades- a fresh approach may inspire alternative approaches to policy in the future.

\section{ACKNOWLEDGMENTS}

This study is supported by the National Affordable Housing Consortium, and the Sustainable Living Infrastructure Consortium. Throughout the process, their input and support will and has been invaluable. 
MacAskill et al., Enhancing Residential Operational Utility Efficiency for Low-income Households. A Integrated Systems Thinking Approach.

\section{REFERENCES}

ABS (2016). "Australian Consumer Price Index." 6401.0.

EME (2016). "Energy Made Easy Web Search."

Eslake, S. (2013). Australian Housing Policy: 50 Years of Failure.

National Housing Strategy (1992). National Housing Strategy Social Housing Workshop, Melbourne Report on outcomes of Social Housing Workshop, Canberra, A.C.T, National Housing Strategy.

Sahin, O., et al. (2017). "A systems approach for assessing water conservation potential through demandbased water tariffs." Journal of Cleaner Production 148: 773-784.

Sahin, O. and S. A. M. Mohamed (2013). "A spatial temporal decision framework for adaptation to sea level rise."

Sterman, J. (2000). Business dynamics: systems thinking and modeling for a complex world. Boston, Irwin/McGraw-Hill.

Yates, J. (2008). "Australia's Housing Affordability Crisis." The Australian Economic Review 41(2): 200214.

Yates, J. (2016). "Why Does Australia Have an Affordable Housing Problem and What Can Be Done About It?" Australian Economic Review 49(3): 328-339. 